ORIGINAL PROF-2095

\title{
MECONIUM STAINED LIQUOR;
}

Neonatal outcome

Dr. Iram Aslam

ABSTRACT... The Presence of meconium in amniotic fluid is a risk factor for intrapartum hypoxia. It had been considered as an indicator of poor neonatal outcome. Objective: To determine neonatal outcome in meconium stained liquor. Design: Descriptive Study. Setting: Department of Gynae and Obstetrics, Fatima Memorial Hospital, Lahore. Period: 06 months from 21-01-2009 to 20-07-2009. Subjects and Methods: The patients with meconium stained liquor were assessed by per speculum examination and were followed till the time of delivery. Neonatal outcome was assessed by APGAR scores at 1 minute, vocal cord staining, admission to ICU Nursery, perinatal death, need of resuscitation and total stay in ICU Nursery. Results and Conclusion: During the study period, 140 patients were included in study. Among these, 97 babies had APGAR score $<5$ at 1 minute, 102 babies had staining of vocal cord while 119 babies were admitted to ICU Nursery. Incidence of perinatal death was $8.6 \%$. Conclusions: Meconium stained liquor is associated with poor neonatal outcome.

Key words: APGAR score

Article Citation

Aslam I. Meconium stained liqour; Neonatal outcome . Professional Med J 2013;20(2): 202-207.

\section{INTRODUCTION}

Meconium is composed of swallowed amniotic fluid debris, bile pigments and residues from intestinal secretion. It occurs in approximately $12 \%$ of all fetuses $^{1}$ and in $0.5 \%$ of these, the meconium is aspirated into fetal lungs. Meconium passage requires our special attention as it is associated with increased chances of baby born with poor APGAR scores, needing resuscitation at birth, admission to ICU Nursery and perinatal death.

A number of risk factor have been associated with passage of meconium e.g. PIH. IUGR, prolonged labour, gestational age $>42$ wks $^{2}$. Meconium is an indicator of fetal hypoxia but fetal blood sampling is important to differentiate hypoxic from non hypoxic fetus thus avoiding annecessary intervention ${ }^{3}$.

The presence of meconium in liquor is not associated with an increased incidence of fetal acidosis ${ }^{4}$, the labours that develop academia usually do so after the onset of an abnormal FHR pattern ${ }^{5}$.

The state of fetus is best monitored by a combination of continuous recording of FHR with fetal blood sampling when necessary, to confirm any suspicion of hypoxia ${ }^{6}$.
Various methods have been tried to detect presence of meconium in liquor and to prevent MAS, like amnioscopy, detection by USG, early induction of labour, aggressive oropharyngeal suction and amnioinfusion. Intrapartum amnioinfusion dilutes meconium stained amniotic fluid significantly and been studied as an additional tool to prevent meconium aspiration syndrome ${ }^{7}$.

Early identification of high risk cases with improved neonatal and perinatal care can decrease high perinatal mortality ${ }^{8}$.

Aspiration of meconium was thought by many authors to occurs at delivery as the newborn infant took its first breath $^{9}$. The fetus may also inhale meconium by deep irregular breathing in utero, not initiated by hypoxia. These breaths become more frequent as gestation advances and comprise $10 \%$ of all fetal breathing movements ${ }^{10}$.

Babies born with meconium stained liquor needs nasopharyngeal suction. It is more important to position the infant head and neck so that head is gently extended ${ }^{11}$.

In our study, we sought to assess significance of 
meconium stained liquor in relation with neonatal outcome. In view of large number of patients having meconium stained liquor, study becomes desirable with the aim of having an insight into neonatal outcome in term of APGAR scores, vocal cord staining and ICU nursery admissions.

\section{MATERIAL AND METHODS \\ Study Design \\ Descriptive study}

\section{Setting}

Department of Gynae and Obstetrics, Fatima Memorial Hospital, Lahore.

\section{Sample Size}

The calculated sample size with $5 \%$ margin of error, 95\% confidence level, taking expected \%age of APGAR score $<5$ at 1 minute i.e. $10 \%$ is 140 cases of meconium stained liquor.

\section{Duration of Study}

Study was carried out for a period of 6 months from 21-1-2009 to 20-7-2009.

\section{Sample Selection}

\section{Inclusion Criteria}

- $\quad$ Gestation 37 weeks or more (on Ultrasound)

- $\quad$ Singleton pregnancy (on ultrasound)

- $\quad$ Cephalic presentation (on Ultrasound)

- $\quad$ Having ruptured membrane with meconium stained liquor at any stage or labour (on per speculum examination)

- $\quad$ Patients upto parity of 3

\section{Exclusion Criteria}

- Anomalous baby (e.g. nural tube defect, cardiac anomalies detected on ultrasound)

- Previous caesarean section (assessed through history and documents of previous caesarean section)

- $\quad$ Oligohydramnios (AFI $<7 \mathrm{~cm}$ on ultrasound)
- $\quad$ Diagnosed cases of pre-eclampsia (BP > 140/100) proteinura $0.3 \mathrm{gm} / \mathrm{l}$ diagnosed on dipstick)

- $\quad$ Diagnosed cases of gestational diabetes (BSL $>180 \mathrm{mg} / \mathrm{dl}$ )

\section{RESULTS}

This was a descriptive study conducted at Fatima Memorial Hospital Lahore from 21st January 2009 to 20th July 2009.

During this period, 140 patients having meconium stained liquor at any stage of labour, diagnosed via per speculum examination were included in the study.

When patients were distributed according to age, there were 23 patients who were less than 20 years of age making 16.5\% in age group of 21-30, there were 102 patients $(72.8 \%)$ while $31-40$ years age group contained 15 patients (10.7\%) (Table-I).

\begin{tabular}{|c|c|c|}
\hline Age (Years) & No. of Patients & $\%$ \\
\hline$<20$ & 23 & 16.5 \\
\hline $21-30$ & 102 & 72.8 \\
\hline $31-40$ & 15 & 10.7 \\
\hline Total & 140 & 100 \\
\hline \multicolumn{2}{|c|}{ Table-I. Distribution of Subjects by age } \\
\hline
\end{tabular}

Patients were classified according to gravidity. In this study, 46 patients were primigravida (32.9\%). In group of G2-G3, there were 78 patients $(55.7 \%)$ in G4-G6 group, there were 10 patients $(7.1 \%)$ and only 6 patients (4.3\%) had gravidity more than 6 (Table-II).

When APGAR score of neonates were noted at 1 minute. No of patients who had APGAR score $<5$ at minute were 97 (69.3\%) and 43 patietns had APGAR score $>5$ at 1 min making $30.7 \%$ (Table-III).

Table-IV shows frequency of vocal cord staining 
among neonates who were born to mothers having staining of vocal cords were $102(72.8 \%)$ while 38 neonates had no vocal cord staining (27.2\%).

In this study, 118 neonates required resuscitation (84.3\%) while 22 patients did not need resuscitation making 15.7\% (Table-V).

\begin{tabular}{|c|c|c|}
\hline Gravidity & No. of Patients & $\%$ \\
\hline Primigravida & 46 & 32.9 \\
\hline G2 - G3 & 78 & 55.7 \\
\hline G4 - G6 & 10 & 7.1 \\
\hline > G6 & 6 & 4.3 \\
\hline Total & 140 & 100 \\
\hline \multicolumn{2}{|c|}{ Table-II. Distribution of patients by Gravidity } \\
\hline
\end{tabular}

\begin{tabular}{|c|c|c|}
\hline APGAR & No. of Patients & $\%$ \\
\hline$<5$ at 1 minute & 97 & 69.3 \\
\hline$>5$ at 1 minute & 43 & 30.7 \\
\hline Total & 140 & 100 \\
\hline
\end{tabular}

Table-III. Distribution of cases by APGAR Score at

\section{Minute}

\begin{tabular}{|c|c|c|}
\hline Vocal Cord Staining & No. of Patients & $\%$ \\
\hline Present & 102 & 72.8 \\
\hline Absent & 28 & 27.2 \\
\hline Total & 140 & 100 \\
\hline
\end{tabular}

Table-IV. Frequency of vocal cord staining

\begin{tabular}{|l|c|c|}
\hline \multicolumn{1}{|c|}{ Need Status } & No. of Patients & $\%$ \\
\hline Requiring resuscitation & 118 & 84.3 \\
\hline Not requiring resuscitation & 22 & 15.7 \\
\hline Total & 140 & 100 \\
\hline
\end{tabular}

Table-V. Frequency of need of resuscitation
While studying reason for need of resuscitation, it was found that poor cry was the main reason for requirement of resuscitation 73 patients $(61.9 \%)$ while in 45 patients, needed resuscitation due to hypoxia (38.1\%) (Table-VI).

Table-VII shows outcome during perinatal period.

\begin{tabular}{|c|c|c|}
\hline Reason & No. of Patients & \% \\
\hline Hypoxia & 45 & 38.1 \\
\hline Poor Cry & 73 & 61.9 \\
\hline Total & 118 & 100 \\
\hline \multicolumn{2}{|c|}{ Table-VI. Reason for need of resuscitation } \\
\hline
\end{tabular}

\begin{tabular}{|c|c|c|}
\hline & No. of Patients & $\%$ \\
\hline Surviving & 128 & 91.4 \\
\hline Death & 12 & 8.6 \\
\hline Total & 140 & 100 \\
\hline \multicolumn{2}{|c|}{ Table-VII. Outcome during Perinatal Period } \\
\hline
\end{tabular}

\begin{tabular}{|l|c|c|}
\hline \multicolumn{1}{|c|}{ Status } & No. of Patients & $\%$ \\
\hline No NICU Admission & 21 & 15 \\
\hline NICU Admission & 119 & 85 \\
\hline Total & 140 & 100 \\
\hline \multicolumn{2}{|c|}{ Table-VIII. Distribution of Babies according to NICU } \\
Nursery Admission
\end{tabular}

\begin{tabular}{|c|c|c|}
\hline & No. of Patients & $\%$ \\
\hline 1-2 days & 23 & 19.3 \\
\hline 3-4 days & 55 & 46.2 \\
\hline$>4$ days & 41 & 34.5 \\
\hline Total & 119 & 100 \\
\hline \multicolumn{2}{|c|}{ Table-IX. Duration of stay in ICU Nursery } \\
\hline
\end{tabular}

www.theprofesional.com 
Majority of subjects showed good perinatal outcome. Death was observed in 12 neonates (8.6\%). The study highlighted the number of babies who were admitted to ICU nursery.

119 babies (85\%) were admitted to ICU nursery while 21 babies (15\%) shifted with mother (Table-VIII).

When babies were followed in NICU, 23 remained admitted for $1-2$ days (19.3\%), while 55 were kept in NICU for 3-4 days (46.2\%) and no. of babies who remained admitted for more than 4 days were 41 (34.5\%). (Table IX)

\section{DISCUSSION}

The study reviewed neonatal outcome in meconium stained liquor. About 2/3rd of patients were in age group of 21-30 years while less number of patient were found in younger ( $<20$ years) or older (31-40 years) age group. Although no correlation of age with meconium stained liquor were found.

Gonzaloz reports poor APGAR in $56.1 \%$ patients whereas the Georgy in his study showed that $46 \%$ of babies had APGAR score $<6$ at 1 minute and $5 \%$ of babies had APGAR scores of $<5$ at 5 minutes ${ }^{12}$.

According to steer et al, incidence of 1 minute APGAR $<7$ was $19 \%$ but it has been communicated that reduction in 1 minute APGAR score may have been due at least in part to the use of pharyngeal suction and or endotracheal intubation by Pediatrician suppressing spontaneous respiration and thus iatrogenically reducing APGAR score. My study showed that 97 neonates had APGAR scores of $<5$ at 1 minute making $69.3 \%$.

In $76 \%$ of babies with meconium stained liquor, meconium was present below the vocal cords ${ }^{13}$. N. Saqib Qureshi at Liverpool women's Hospital found that meconium aspiration syndrome occurs in upto 1 $3 \%$ of all cass in which meconium stained liqour was seen. This study showed that vocal cord staining with meconium was found in $15.7 \%$ of the babies.

In another study, meconium was found below trachea in $38 \%$ of babies ${ }^{14}$. In our study, $102 \%$ babies had staining of vocal cords making $72.8 \%$. Of all the babies who develop MAS, $4 \%$ die (2\% of all perinatal death) ${ }^{15}$. In our study incidence of perinatal death was $8.6 \%$.

Out of 4289 deliveries, 659 were exposed to meconium and $48 \%$ of infants were intubated. Birth weight, gestational ages at delivery and umbilical artery $\mathrm{pH}$ were similar between intubated and nonintubated neonates. NICU admissions were significantly higher in intubated neonates. All 9 neonates diagnosed with MAS were intubated at birth $^{16}$. In our study 118 neoantes (84.3\%) required same form of resuscitation, 45 due to hypoxia and 73 due to poor cry.

$98 \%$ cases of maconium stained amniotic fluid were admitted to ICU nursery at 37 weeks or later ${ }^{17}$. On the contrary in another study, $9 \%$ of babies were admitted to $\mathrm{NICU}^{18}$.

119 neonates were shifted to ICU nursery in our study making $85 \%$. 23 babies (19.3\%) remained admitted in NICU for one to two days. 55 babies (46.2\%) stayed in NICU for there to four days.

While 41 babies (34.4) remained admitted in NICU for longer than four days.

So meconium is a major contribution to neonatal morbidity and mortality. It is concluded that it is of utmost importance to concentrate to maternal health and antenatal care ${ }^{19}$. In developing part of the world, where poverty, poor patient compliance, nutritional deprivation and unsatisfactory transportation system have all contributed to late prescutation to the hospital, antenatal care to identify high risk pregnancies and quick identification and swift management of high risk 
labour such as with meconium, can improve perinatal health.

\section{CONCLUSIONS}

It is concluded from the above study that meconium stained liquor is associated with poor neonatal outcome as indicated by poor APGAR scores, vocal cord staining, need of resuscitation and ICU nursery admission.

\section{Copyright@ 25 Dec, 2012.}

\section{REFERENCES}

1. Oyelese Y, Culim A, Ananth V, Kaminsky M, Vintzileos A, Smulian J. Meconium stained amniotic fluid across gestation and neonatal acid base status. J Obstet Gynecol 2006; 108: 345-9.

2. Zhu L, Wong F, Bai J. The epideomology of meconium stained amniotic fluid on hospital basis. Zhonggu $\mathrm{Yi}$ Zue ke Zue Yvan Bao 2003; 25: 63-5.

3. Sheikh SM, Kamaruddin A, Setna F, Riaz. Role of pathological CTG in evaluating fetal well being. $\mathrm{J}$ Coll Physician Pak 2006; 16: 404-7.

4. Steer P.J. Has the expression "fetal distress" out lived its usefulness? BJOG 1982; 89: 690-93.

5. Fleischer A, Schulman H, Jagani N. The development of fetal acidosis in the presence of abnormal fetal heart rate tracing. Am J Obstet Gynecol 144: 55-60.

6. Figo. Guidelines for the use of fetal monitoring. Int $J$ Gynecol Obstet 1987; 25: 149-67.

7. J Jbstet Gynecol India 2006; 56: 128-30.

8. Majeed R, Memon Y, Majeed F, Naheed T. Risk factors for birth Asphyxia. J Ayub Med Coll Abottabad 2007; 19.

9. Gregory G.A, Gordding C.A, Phibbs RH, Rolley WH. Meconium aspiration in infants - a prospective study. J Pediatr 1974; 85: 849-52.
10. Dawes G.S, Fox H.E, Leduce BM. Liggins. GC, Richard RT. Respiratory movement and rapid eye movement deep in the fetal lamb. J Physiol 1972; 220: 119-43.

11. Colim PH, Od Onnel, Omar F, Kamlin, Peter G, Collin J Morlay. Endotracheal intubation attempt during Neonatal resuscitation. Am J pediatr 2000; 117: 1621.

12. David N, Njokanman F, Iroha E. Incidence of and factors associated with meconium staining of amniotic fluid in Nigerian University Teaching Hospital. J Obstet Gynecol 2006; 26: 518-20.

13. Hageman J. Contey M. Francis K, Stense J Wolf I, Santi $V$ et al. Delivery room management of meconium staining of amniotic and the development of meconium aspiration syndrome. J Perinatol 1988; 8 : 127-31.

14. Malik AS, Hillman D. Meconium aspiration syndrome and neonatal outcome in developing countries. Ann tropical Pediatrics 1944; 14: 47-51.

15. Mechael GR. Meconium Aspiration Syndrome. More than intrapartum meconium. N Engl J Med 2005; 353 : 946-8.

16. Peng T, Gutcher G, Gorsten V, J. A selective aggressive approach to neonate exposed to meconium stained amniotic fluid. Am J Obstet Gynecol 1996; 175: 296303.

17. Metthew TG. Warshaw JB. Relevance of gestational age and distribution of meconium passage in utero. $J$ Pediatr 1979; 64: 30-1.

18. Tan P, Suguna S. Vallikkannu N, Hassan J. Predictors of newborn admission after labour induction at term: bishop score, pre induction ultrasonography and clinical risk factors. Singapore Med J 2008; 49: 193.

19. Ejaz I, Khan JH, Baloch RG. Neonatal mortality: Report from a tertiary hospital in Lahore Causes and outcome. Pak Paed J 2001; 25: 35-8. 


\section{AUTHOR(S):}

DR. IRAM ASLAM, MBBS, FCPS

Senior Registrar

Department of Gynae \& Obstetrics

Independent University Hospital,

Faisalabad

\section{Correspondence Address:}

Dr. Iram Aslam

MBBS, FCPS

Senior Registrar

Department of Gynae \& Obstetrics

Independent University Hospital

Faisalabad

iram.usman@hotmail.com
Article received on: 03/10/2012 Accepted for Publication: 25/12/2012 Received after proof reading: 04/02/2013

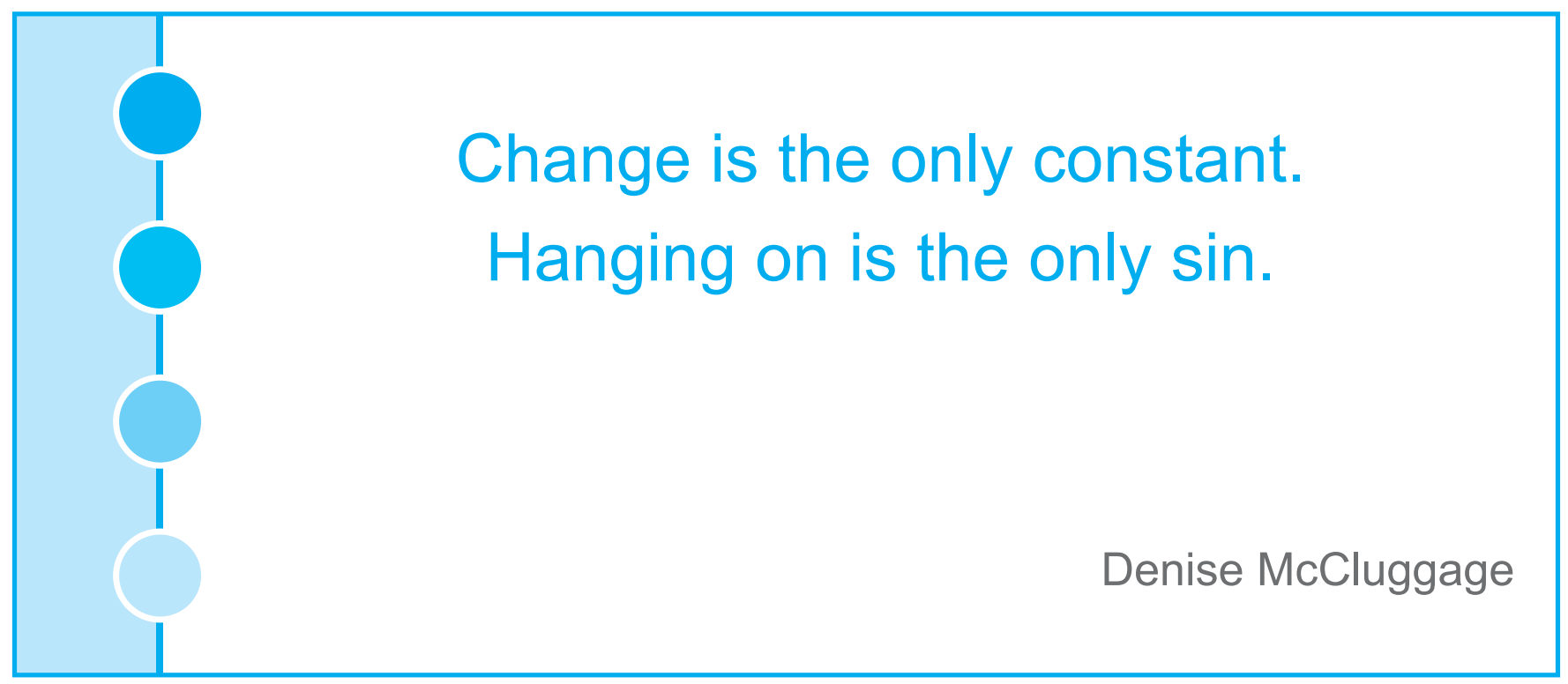

